\title{
Robustness of future atmospheric circulation changes over the EURO-CORDEX domain
}

\author{
Tugba Ozturk ${ }^{1,2,3}$ (D) Dominic Matte ${ }^{1,3} \cdot$ Jens Hesselbjerg Christensen ${ }^{1,3,4}$
}

Received: 10 September 2020 / Accepted: 18 November 2021 / Published online: 25 November 2021

(c) The Author(s) 2021

\begin{abstract}
European climate is associated with variability and changes in the mid-latitude atmospheric circulation. In this study, we aim to investigate potential future change in circulation over Europe by using the EURO-CORDEX regional climate projections at $0.11^{\circ}$ grid mesh. In particular, we analyze future change in 500-hPa geopotential height $(\mathrm{Gph}), 500-\mathrm{hPa}$ wind speed and mean sea level pressure (MSLP) addressing different warming levels of $1{ }^{\circ} \mathrm{C}, 2{ }^{\circ} \mathrm{C}$ and $3{ }^{\circ} \mathrm{C}$, respectively. Simple scaling with the global mean temperature change is applied to the regional climate projections for monthly mean 500-hPa Gph and 500-hPa wind speed. Results from the ensemble mean of individual models show a robust increase in 500-hPa Gph and MSLP in winter over Mediterranean and Central Europe, indicating an intensification of anticyclonic circulation. This circulation change emerges robustly in most simulations within the coming decade. There are also enhanced westerlies which transport warm and moist air to the Mediterranean and Central Europe in winter and spring. It is also clear that, models showing different responses to circulation depend very much on the global climate model ensemble member in which they are nested. For all seasons, particularly autumn, the ensemble mean is much more correlated with the end of the century than most of the individual models. In general, the emergence of a scaled pattern appears rather quickly.
\end{abstract}

Keywords Atmospheric circulation $\cdot$ Climate change $\cdot$ EURO-CORDEX $\cdot$ Regional climate modeling

\section{Introduction}

As anthropogenic climate change becomes more evident, research now focuses on prediction of climate impacts at the regional scale as well as detection and attribution of climate change. There is confidence in detection of change of global surface temperature, which is mainly governed by thermodynamics (IPCC 2013). However, the picture of the changes in precipitation provided by climate projections is still blurry (Shepherd 2014; Kjellström et al. 2013). Extra-tropical regional climate is primarily controlled by

Tugba Ozturk

tugba.ozturk@isikun.edu.tr

1 Physics of Ice, Climate and Earth, Niels Bohr Institute, University of Copenhagen, Copenhagen, Denmark

2 Department of Physics, Faculty of Arts and Sciences, Isik University, 34980 Istanbul, Turkey

3 Danish Meteorological Institute, Copenhagen, Denmark

4 NORCE, Norwegian Research Centre, Bjerknes Centre for Climate Research, Bergen, Norway large-scale atmospheric circulation, including the positioning of jet streams and storm tracks. Increases in the number of extreme weather events and their intensity have inspired many studies to investigate the link between changes in atmospheric circulation and occurrence of extreme events (e.g., Francis and Vavrus 2012; Christensen et al. 2013; Horton et al. 2015; Lehmann and Coumou 2015).

European climate very much depends on the mid-latitude atmospheric circulation. It is controlled mainly by westerly flow which brings moist maritime air from the Atlantic Ocean, while easterly flow is associated with dry and cold weather in winter and warm weather in summer. Atlantic storms or lack thereof have a key role on the occurrence of extreme weather events over Europe, such as the European heat wave in 2003 (Schaer et al. 2004; Stott et al. 2004), the flooding in UK in 2007 (Blackburn et al. 2008) and the drought in southern Europe in 2012 (Dong et al. 2013). The North Atlantic Oscillation (NAO) also influences interannual and decadal variability over the region (e.g., Hurrell 1995). Studies show that there is a link between the positive phase of the NAO and milder and wetter winter climate in Northern and Western Europe and colder and 
drier conditions in the southwestern Europe and the Mediterranean (Kjellström et al. 2013). The wintertime NAO is generally projected to be more positive along with global warming (Meehl et al. 2007; Christensen et al. 2013). On the contrary, during summer CMIP5 models exhibit a decrease in mid-latitude zonal flow under climate change for a highemission scenario (Coumou et al. 2015).

Several projects in the last two decades have provided future climate information over the European domain using regional climate projections (Christensen and Christensen 2007; Deque et al. 2007; Kjellström et al. 2011; Jacob et al. 2014; Coppola et al. 2021). Results show a robust increase in temperature most pronounced for northern Europe in winter and over southern Europe in summer. Climate models project an enhanced near-surface summer warming and drying over the Mediterranean compared to the rest of Europe by the end of the century. This north-south warming gradient which is referred to as the Mediterranean amplification leads to a decrease in precipitation over southern Europe in summer (Brogli et al. 2019). Model results are in a good agreement in projecting future warming over Europe, but they tend to diverge more for future change of precipitation (Christensen et al. 2013, 2019; Kjellström et al. 2018; Matte et al. 2019). Disagreements among model projections are associated with uncertainties in the climate forcing, the inherent climate sensitivity, internal variability of the climate system and parameterization schemes used in climate modeling (e.g., Hawkins and Sutton 2009). The increase in extreme weather events over Europe in the last decade (Beniston et al. 2007; Fischer and Schär 2010; Rajczak and Schär 2017; Spinoni et al. 2018) underlines the importance of understanding physical mechanisms driving European climate at multi decadal timescales. Thus, it is very relevant to investigate the projected future change of circulation and its link to the change in temperature and precipitation. It is worth noting that biases in the mean circulation can be the result of decadal-scale natural variability but also indications for model deficiencies and affect particularly precipitation results (e.g., van Ulden and van Oldenborgh 2006).

Following the approach by Matte et al. (2019), our aim is to analyze simulated changes in atmospheric circulation by investigating the ensemble mean and individual model results of the EURO-CORDEX simulations for circulation related variables scaled by global mean temperature changes. We have focused on the geopotential height, directional wind components at $500-\mathrm{hPa}$ and mean sea level pressure variables. The geopotential height field can be used to depict the general atmospheric circulation. As climate warms, the warming signal will dominate the overall changes in geopotential height at some point, i.e., an increase in the height will be expected everywhere (Giorgi and Lionello, 2008; Frederiksen et al. 2018). However, certain gradients of geopotential heights may emerge, which would imply a change in the thermal winds and the general circulation caused by climate change. Once there is unequivocal warming everywhere, pattern scaling could help to see if emerging height field anomalies are robust, with implications for the circulation as well. Kjellström et al. (2013) showed that robust climate change signals in e.g., temperature and precipitation, emerge above the natural variability at different points in time. However, the timing may be related to models' climate sensitivity. Using a simple scaling approach, such as the one used in this study, may reveal patterns before formally emerging in a statistical sense from their inter-model variability (e.g., Matte et al. 2019).

There is a close relationship between 500-hPa Gph and MSLP. 500-hPa Gph field is a combination of warming signal and surface pressure signals. By applying a pattern scaling approach to the 500-hPa Gph field, we aim to see emergence of a circulation signal. On the other hand, surface pressure is not expected to scale with global mean temperature on longer time scales. We therefore present the correlation of ensemble mean of model projections of scaled patterns with the end of the century patterns as introduced by Matte et al. (2019). The emergence of scaled patterns from the noise when correlated with the end-of-century patterns are investigated, also for individual members, to address the robustness of the climate change signal. Finally, to assess whether projected changes are considered robust and in line with observations, we investigate how circulation has changed during the last 40 years using the ERA5 (Hersbach et al. 2019) reanalysis dataset. Difference between the last and the first 20 years of available data is calculated and scaled using global mean temperature trends to address changes in atmospheric circulation. Comparison of ensemble mean model results with observed trends is also done for the last 20 years, a period with a strong global warming trend. This is also done to identify if there would be any seasons where pattern scaled model projections appear to represent current observed trends well.

\section{Data and methodology}

\subsection{Datasets}

The monthly mean 500-hPa geopotential height, 500-hPa wind fields and mean sea level pressure from the EUROCORDEX (Jacob et al. 2014) experiments at $0.11^{\circ}$ grid mesh are used for the RCP 8.5 (Representative Concentration Pathway- $8.5 \mathrm{~W} / \mathrm{m}^{2}$ ) scenario. Projected changes in seasonal mean of circulation variables for the period of 2080-2099 compared to the reference period of 1985-2004 are investigated for the EURO-CORDEX domain using 42 realizations of regional climate simulations (Fig. 1). Ensemble mean of all future changes was calculated for 
1 realisation 2 realisations 3 realisations

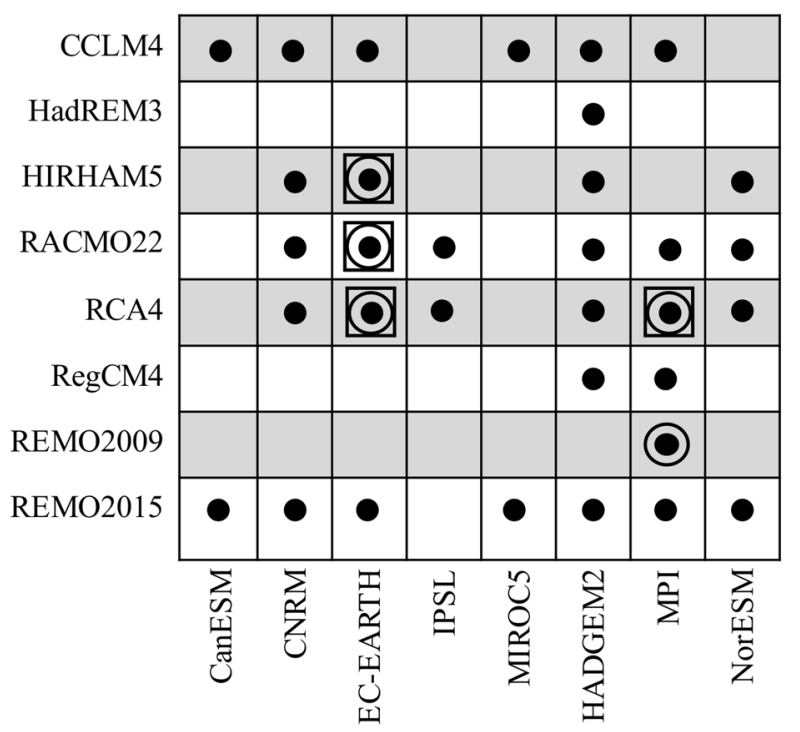

Fig. 1 GCM/RCM Matrix

each season. Some of the regional climate model simulations driven by the CNRM-CM5 global climate model ensemble member r1i1p1 (e.g. REMO2015, RCA4 and CCLM4) give different results from other model results (e.g. HIRHAM5 and RACMO22E). It is worth noting that this is likely related to the fact that REMO2015, RCA4 and CCLM4 have used erroneous lateral boundary conditions from CNRMCM5 even though it has no remarkable impact on ensemble mean (Christensen and Kjellström 2020). The ERA5 dataset for the period of 1980-2019 was also used to see changes of circulation in the last 20 years compared to the first 20 years of the dataset.

\subsection{Methods}

\subsubsection{The pattern scaling approach}

The pattern scaling approach is defined as the change of the 20-year mean (relative to 1985-2004) divided by the global mean temperature change of the associated global climate model ensemble member in the GCM-RCM pair (see e.g., Matte et al. 2019). This approach was applied to changes in the 500-hPa geopotential height and changes in the 500$\mathrm{hPa}$ wind fields, while changes in the mean sea level pressure fields were not scaled. Unlike temperature that could be argued to scale more or less with the forcing, we do not a priori expect to see any change in mean sea level pressure that will scale linearly due to the forcing. However, the change in the 500-hPa geopotential height is sensitive to the warming of the lower atmosphere, so that it is expected to scale with increasing forcing/global temperature. Changes in winds are also likely to scale as the wind anomalies at 500-hPa are at least partly the result of the differential warming pattern. The pattern scaling is also applied to the ERA5 dataset, where scaled patterns of 500-hPa Gph and 500-hPa wind speed are calculated using the global mean temperature change between the last 20 years and the first 20 years of 40-year period of 1980-2019 (in this case meaning upscaling by $\left.1 / 0.38^{\circ} \mathrm{C}\right)$.

\subsubsection{The different warming levels}

In this approach, the 20-years average where the relevant GCM ensemble member, for all GCM-RCM pairs, crosses the selected global climate change, compared to the reference period of $1985-2004$, of $1{ }^{\circ} \mathrm{C}, 2{ }^{\circ} \mathrm{C}$, and $3{ }^{\circ} \mathrm{C}$, respectively, is extracted. We have not identified any multiple crossings as we calculated the 20 -year running mean of global temperature change. A 20 -year mean of the regional climate simulations was then calculated from each pair around the extracted years. They were then scaled by the corresponding global warming levels (Matte et al. 2019).

\subsubsection{Signal-to-noise ratio}

The signal-to-noise ratio $(\mathrm{S} / \mathrm{N})$ is calculated for each scaled field using:

$S / N=\frac{<S P>}{\sigma_{S P}}$

where $<\mathrm{SP}>$ is the ensemble mean of scaled patterns of all the members and $\sigma_{S P}$ is the inter-member standard deviation of the scaled patterns from the model results (Christensen et al. 2019). This $\mathrm{S} / \mathrm{N}$ is then used as a metric to represent the robustness of the climate change pattern.

\section{Results}

\subsection{Simulated seasonal change of scaled pattern of circulation fields at the end of the century}

In this section, we analyze the ensemble mean of scaled changes in circulation fields and their robustness by investigating the $\mathrm{S} / \mathrm{N}$. Figure 2 shows the ensemble mean of scaled change in 500-hPa Gph for the end of the century with gray shading indicating the areas at which $\mathrm{S} / \mathrm{N}<1$. Figure 3 shows the ensemble mean of the 500-hPa wind speed for reference and future period together with changes and the scaled changes to see the magnitude and direction of the 
Fig. 2 Scaled patterns of 500$\mathrm{hPa} \mathrm{Gph}$ for the period of 2080 2099 compared to $1985-2004$ for four seasons (a-d) (a)

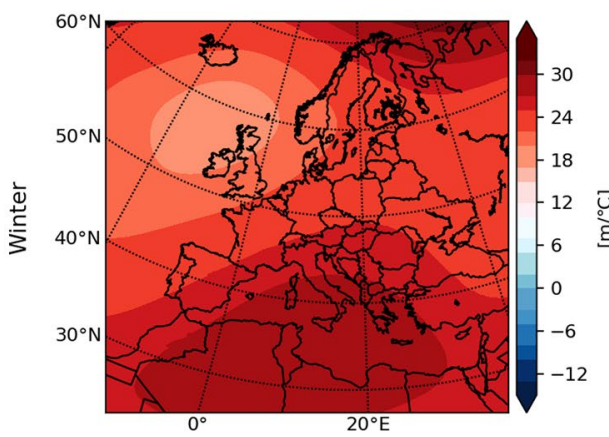

(c)

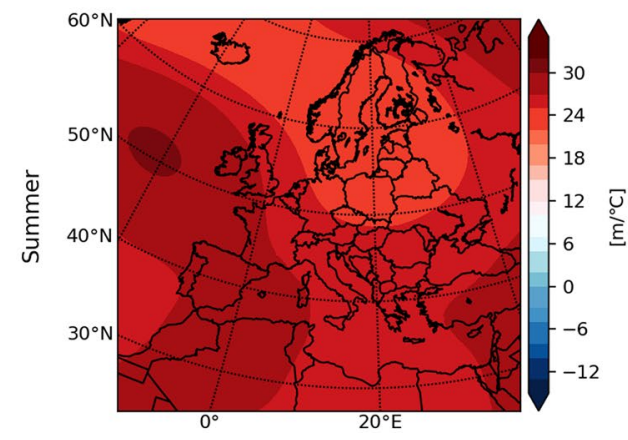

(b)

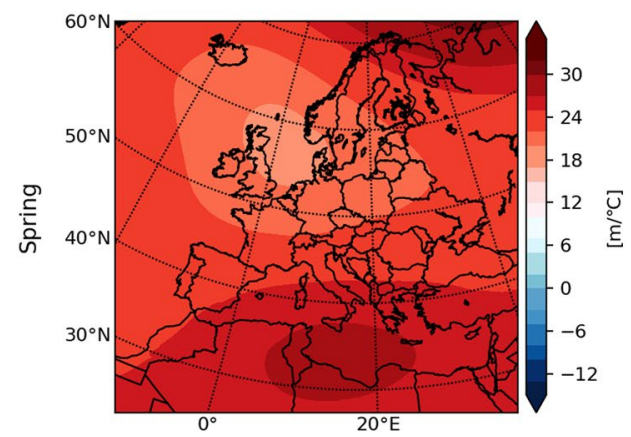

(d)

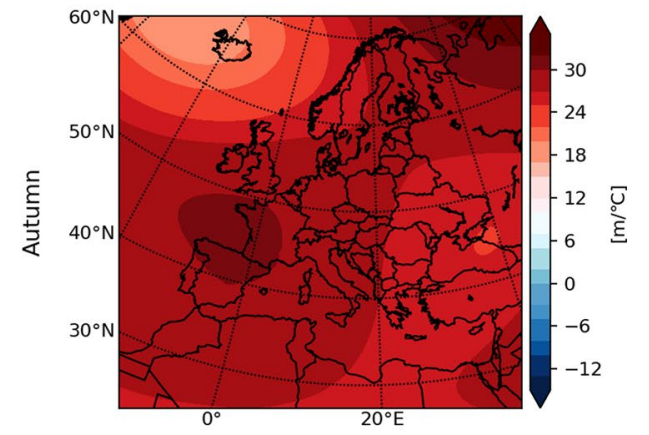

field itself. Ensemble mean changes in MSLP for the end of the century compared to the reference period is also shown in Fig. 4.

The end century scaled patterns for the 500-hPa Gph for four seasons are showing a positive change where the lack of gray shaded areas is an indication of robustness (see Fig. 2). It means that the atmosphere below the 500-hPa will be extending vertically due to warmer conditions in the future compared to the present regardless of any changes in the surface pressure. There are very clear horizontal differential signals in the height fields indicating that changes in wind (by the thermal wind relationship) are expected over areas where gradients in the height field are located. Even though 500-hPa Gph changes show clear signals, changes in wind have relatively small $\mathrm{S} / \mathrm{N}$.

In winter and spring, there is a differential warming in 500-hPa Gph with a relatively high increase over the Mediterranean (Fig. 2a, b). As a result of this differential warming, ensemble mean results tend to have an enhanced westerly flow, meaning that it brings warm and moist air, being transported into the Mediterranean and central Europe (Fig. 3c-d, g-h). Increased westerlies seem to be robust especially during spring (Fig. 3h). MSLP (Fig. 4a, b) also shows an increase over the Mediterranean for both winter and spring, indicating enhanced anticyclonic circulations which leads to more stable conditions (Giorgi and Lionello 2008). There is already a high pressure over the Mediterranean in winter (Supplementary Fig. 1a). The original high-pressure pattern has its center over Northern Africa. According to the results, the high-pressure pattern has not strengthened that much over Northern Africa but strengthened over the Mediterranean (Fig. 4a). Even though it is not a big change, it expands northward, and the biggest part of this change is over the Mediterranean. Enlarging a highpressure pattern makes it even more stable. As a result of this change, the Mediterranean and Central Europe is expected to have a decrease in precipitation, which is indeed in line with most model projections (e.g., Christensen et al. 2013).

For the northern part of the domain, the area of relatively low wind speed is widening in the future and getting even lower in winter (Fig. 3a, b). It is a robust weakening of the westerlies most likely associated with the Arctic amplification of the warming. As increase in Arctic geopotential heights is shown (Fig. 2a, b), the poleward pressure gradient is expected to be reduced in the troposphere weakening the storm tracks and westerly jet at high latitudes (Fig. 3c, d) (Coumou et al. 2018). We also identify a significant increase in MSLP over the northern part meaning that the Icelandic low is weakened and shifted northward in winter and more robustly so in spring (Fig. $4 \mathrm{a}, \mathrm{b}$ ).

There is relatively less warming (or a local low) in the 500-hPa Gph field in winter (Fig. 2a) over the British Isles where cyclonic circulation is enhanced. This is associated with the enhanced flow which reinforces the supply of relatively warm and moist air from the southwest over the British Isles (Fig. 3c, d). It brings the warm air from 

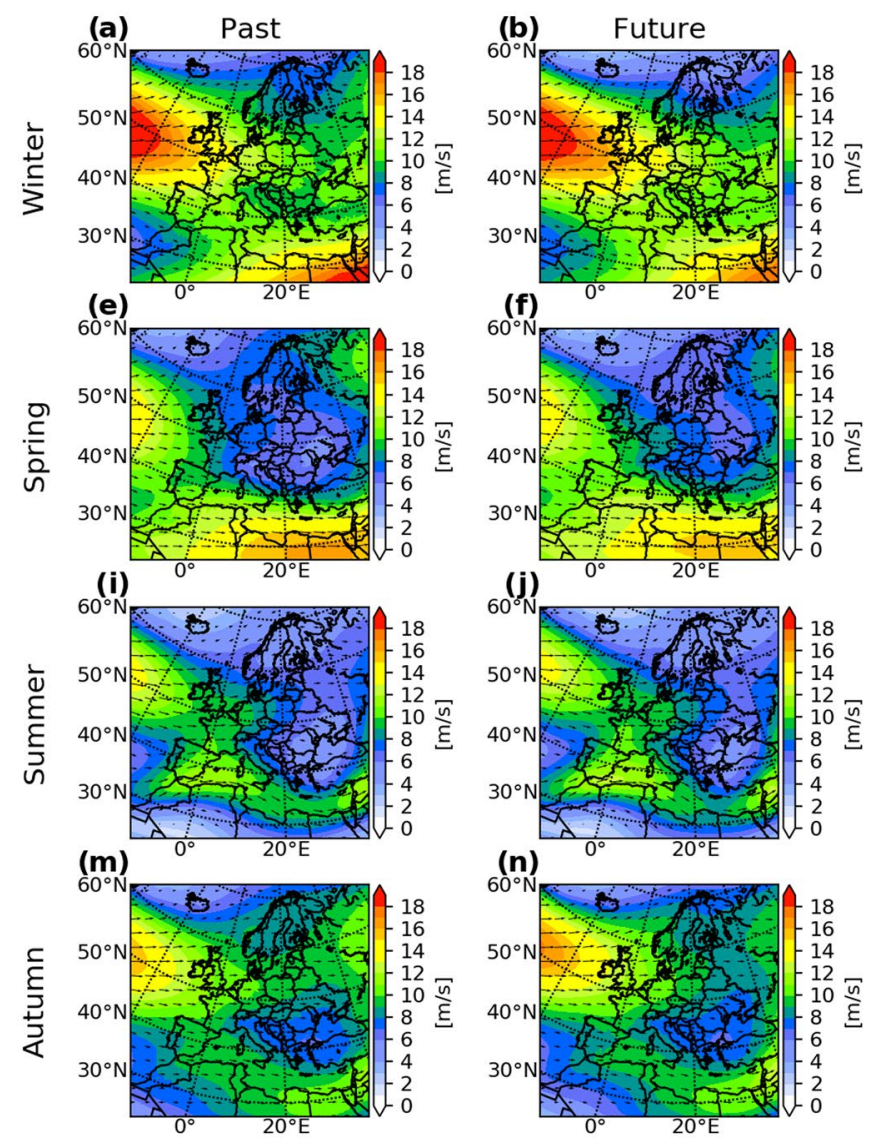

Fig. 3 Absolute values of 500-hPa wind speed for the reference period of 1985-2004 (a, e, i, m), for the future period of 2080-2099 $(\mathbf{b}, \mathbf{f}, \mathbf{j}, \mathbf{n})$. Future change in $500-\mathrm{hPa}$ wind speed for the period of

the southwest into western Europe. This can be associated with strong increase in temperature over the north part of the domain in winter, that also reflects the northward retreat of the snow line (Christensen et al. 2015, 2019; Matte et al. 2019).

For the summer and autumn, a little less warming is observed over the North Atlantic and Scandinavia in the 500-hPa Gph fields compared to rest of Europe (Fig. 2c, d). Meanwhile, relatively cold air masses are transported from the northern part of Atlantic to inland areas (Fig. 3k, o). It might be connected with bringing cold air mass there, that we see this differentiation of warming, consistent with the relative increase in the MSLP over the northwestern part of the domain in summer and autumn (Fig. 4c, d). Figure 3 (third and fourth row) shows only little change in the wind field over the Mediterranean and Europe during summer and autumn, indicating that on average not much change is projected over Europe. Significant increase in MSLP over the North Atlantic is projected for summer and more
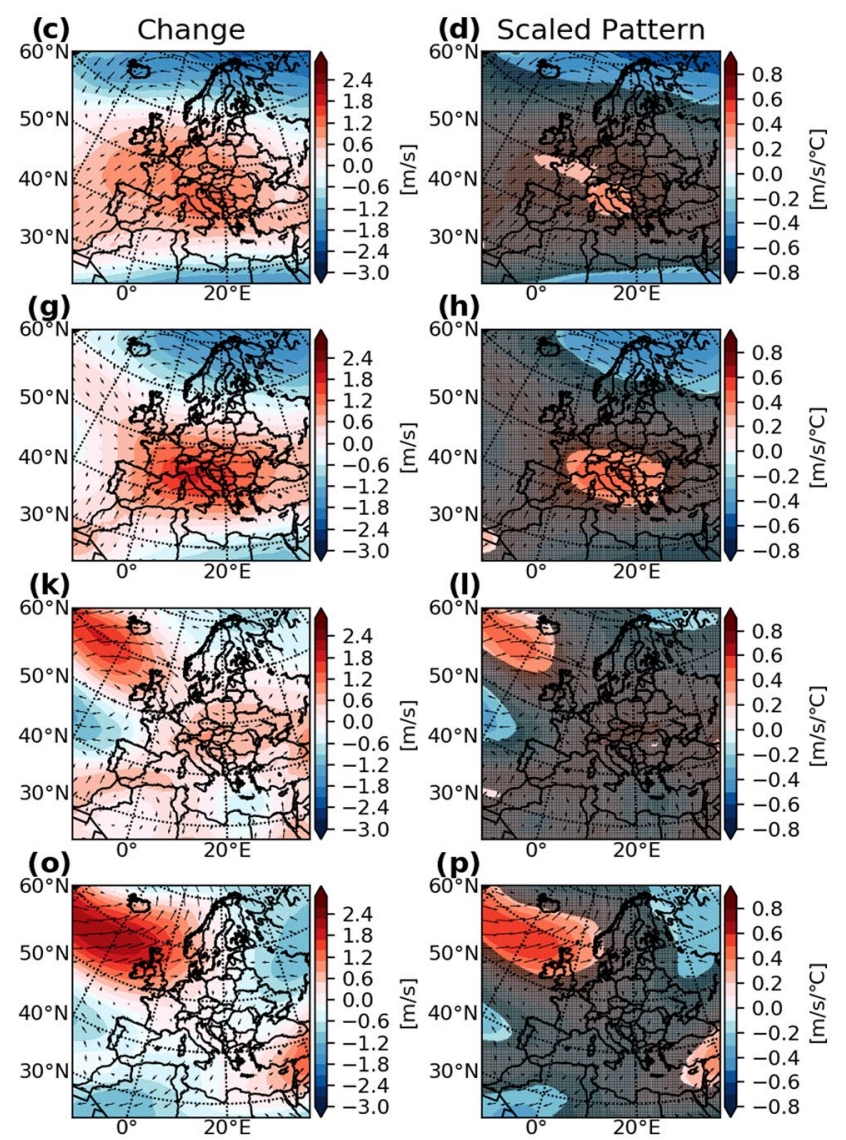

2080-2099 compared to 1985-2004 (c, g, k, o) and scaled patterns of change $(\mathbf{d}, \mathbf{h}, \mathbf{l}, \mathbf{p})$ for four seasons. Gray shading indicates areas at which $\mathrm{S} / \mathrm{N}<1(\mathbf{d}, \mathbf{h}, \mathbf{l}, \mathbf{p})$

pronounced in autumn together with a strengthening and northward expansion of the Azores high (Fig. 4c, d).

\subsection{Emergence of the end-of-century scaled pattern and spatial correlation of scaled patterns against the end-of-century}

To see the emergence of the scaled patterns, we produced animations showing temporal evolution of the scaled pattern of the 500-hPa Gph (Supplementary Video S1), the 500$\mathrm{hPa}$ wind speed and the mean sea level pressure for winter and summer. All members are also shown in the animation to see the individual emergence of the scaled patterns of 500-hPa Gph (Supplementary Video S2). Overall, even if the pattern is sometimes quite different, the emergence of scaled patterns occurs rather quickly for all members. The pattern emerges before it is formally significantly above the noise-as we have defined it-at the grid point level. As seen in the animations, the pattern is highly controlled by the GCM ensemble member, reflecting that the driving GCM 
Fig. 4 MSLP patterns for the period of 2080-2099 compared to 1985-2004 for four seasons (a-d). Gray shading shows areas at which $\mathrm{S} / \mathrm{N}<1$ (a)

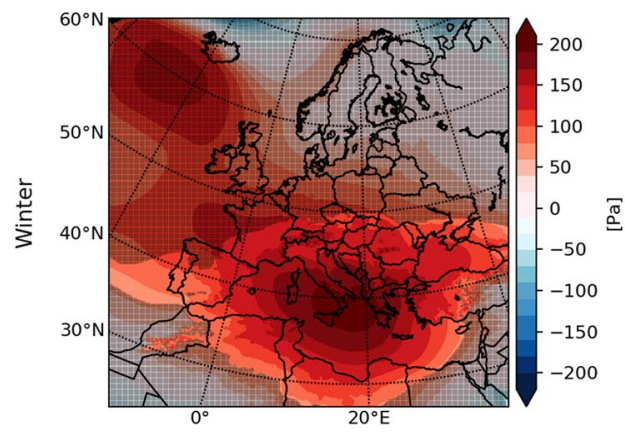

(c)

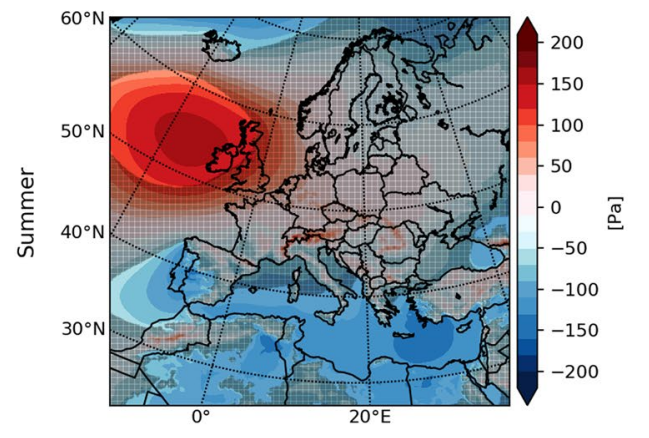

(b)

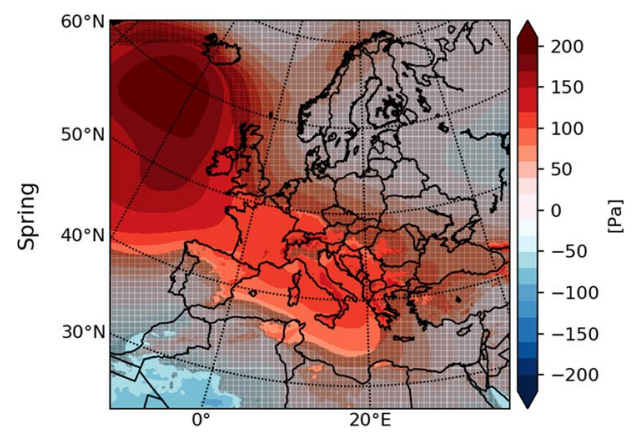

(d)

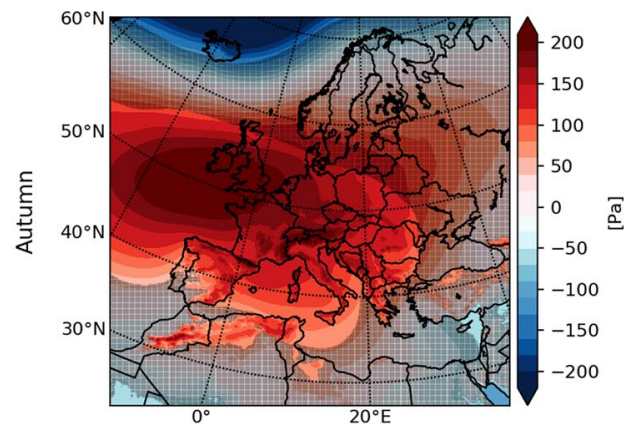

ensemble member provides the large scale forcing of the RCM.

To have a better overview of the emergence of the scaled pattern, we calculate the spatial correlation between a running mean of 20-years scaled patterns from 2006 to 2090 against the corresponding end-period levels (2080-2099). Figure 5 shows spatial correlations of ensemble mean of 500-hPa Gph projections for the four seasons and the yearly mean. Those results suggest that the ensemble mean of model projections is highly correlated with the end-century pattern and showing an early emergence of this pattern, consistent with what is seen in the animations. Winter is the season where the emergence of the pattern is latest, whereas autumn is earliest. The pattern is not emerging until 2050 in winter. On the other hand, it correlates with the end of the century pattern already around 2010 in autumn. This might be related to low sea ice concentration in autumn.

If we look at individual models for each season, we find that the change signal is very much dependent on the GCM ensemble member as it can be seen by the several families of curves in Fig. 6. Spatial correlations show that some members lock to their end-of-century pattern, while others lock to some intermediate patterns before reaching the end of the century. For winter, there are families of lines showing the same trend even if it is an anti-correlation. We clearly see that model results depend very much on GCM ensemble member, since a family of lines belongs to the same GCM ensemble member. Ensemble members of some of the GCMs also have different responses to circulation. For instance, three members of MPI-ESM-LR show very
Fig. 5 Correlation between a running mean of 20 -years ensemble mean of scaled patterns of 500-hPa geopotential height from 2006 to end-period levels (2080-2099)

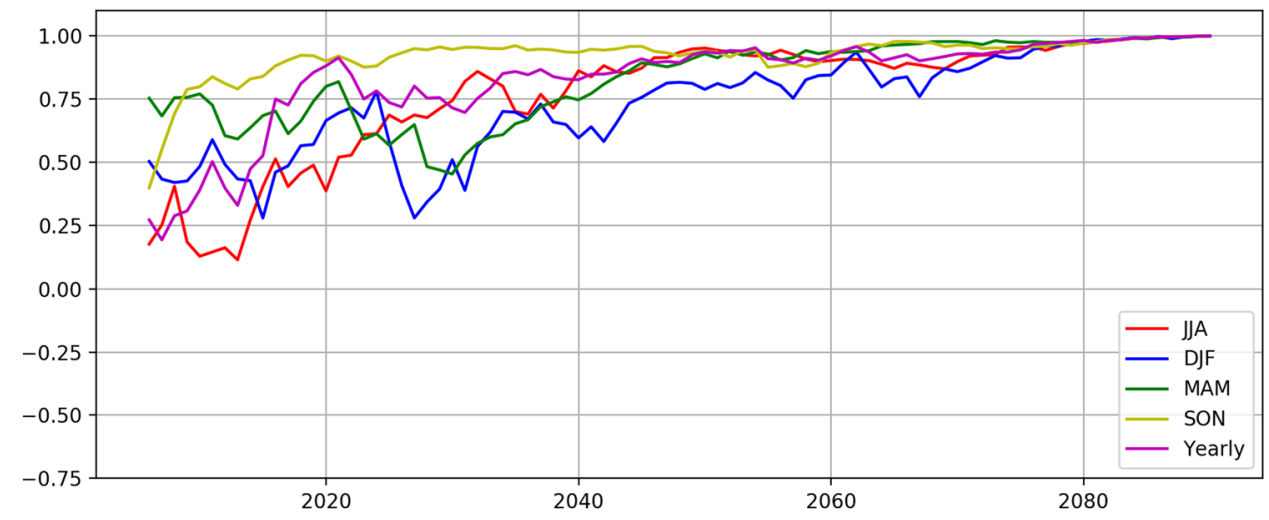


different patterns. Ensemble member r1i1p1 of MPI-ESMLR model (MPI1) is anticorrelated, but it converges towards the end of the century, whereas r2ilp1 (MPI2) is close to the 2100 pattern throughout the simulation and r3i1p1 (MPI3) is converging from around 2040 (Fig. 6). Similarly, ensemble member r12i1p1 of EC-EARTH model (ECEARTH2) has different patterns from other ensemble members with high correlation from the beginning that drops to become non-existing around 2060, from which it grows again. It is interesting to note that one model, NorESM1-M, is not converging until the last 10 years. On the contrary, it is negatively correlated. It is clear that it has a more different largescale circulation compared to the other models. In winter, there is a poleward shift of the storm track and weakening of the baroclinicity which basically tends to make much more southern flow very likely to be the result of reduction in sea ice. NorESM1-M is found to show lower variability in the zones of extratropical storminess and generally projects a northward displacement of the storminess. It is flipping from positive to negative correlation between 2060 and 2080 , indicating some decadal variability. The detailed sea ice retreat in the GCM ensemble members may also play an important role in different responses of models (Iversen et al. 2013), a more detailed analysis is, however, beyond the scope of this paper.

The sea ice effect is not very important in the melt season. Most models have little sea ice during summer and lose most if not all as climate warms. At the same time near-surface temperatures remain close to or only stay slightly above freezing, whether summer ice is present or not. EC-EARTH3
Fig. 6 Correlation between a running mean of 20 -years scaled patterns of individual models and ensemble mean (black line) of 500-hPa geopotential height from 2006 to end-period levels (2080-2099) for winter season
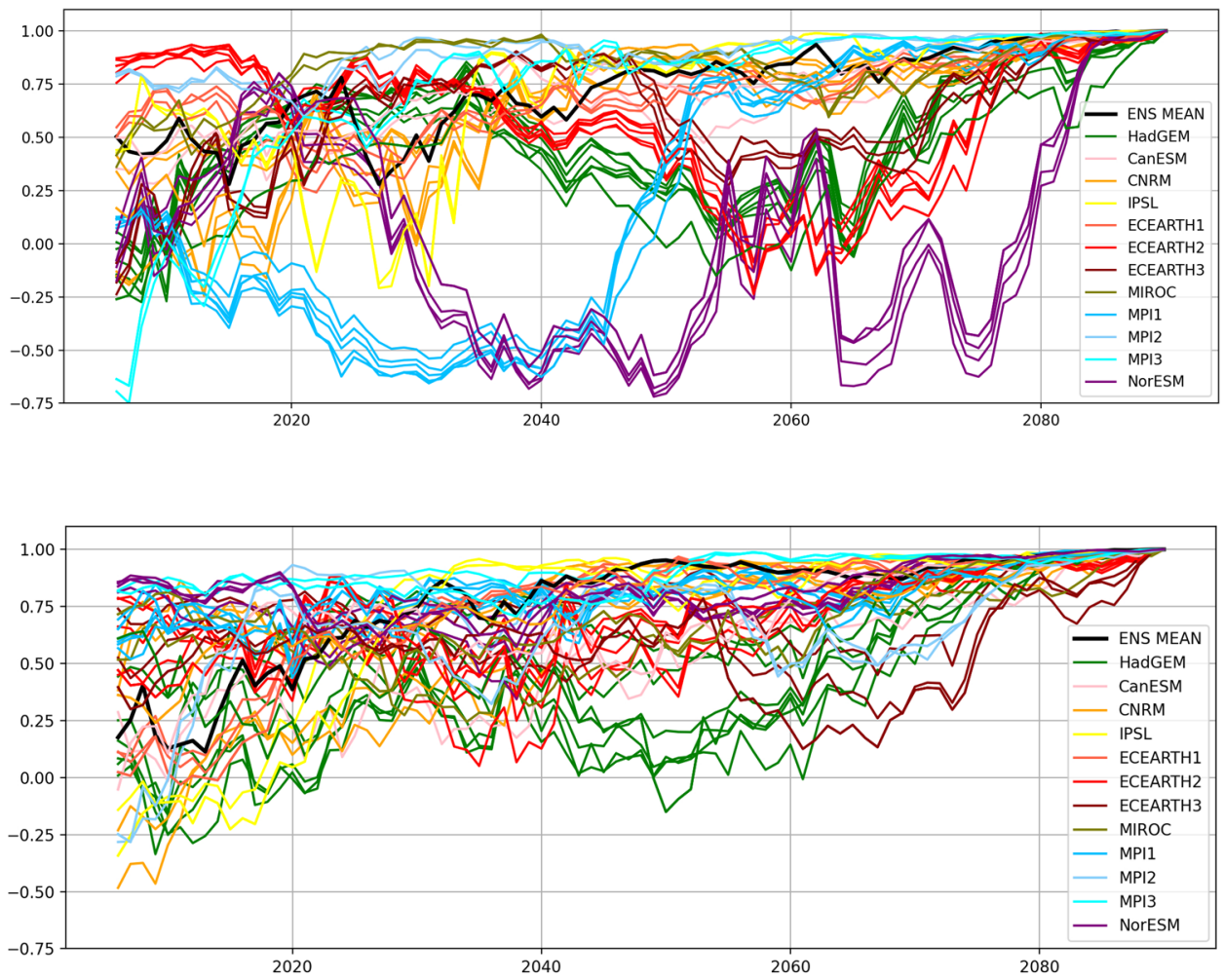

Fig. 7 Correlation between a running mean of 20 -years scaled patterns of individual models and ensemble mean (black line) of 500-hPa geopotential height from 2006 to end-period levels (2080-2099) for summer season

Fig. 8 Correlation between a running mean of 20-years scaled patterns of individual models and ensemble mean (black line) of 500-hPa geopotential height from 2006 to end-period levels (2080-2099) for autumn season

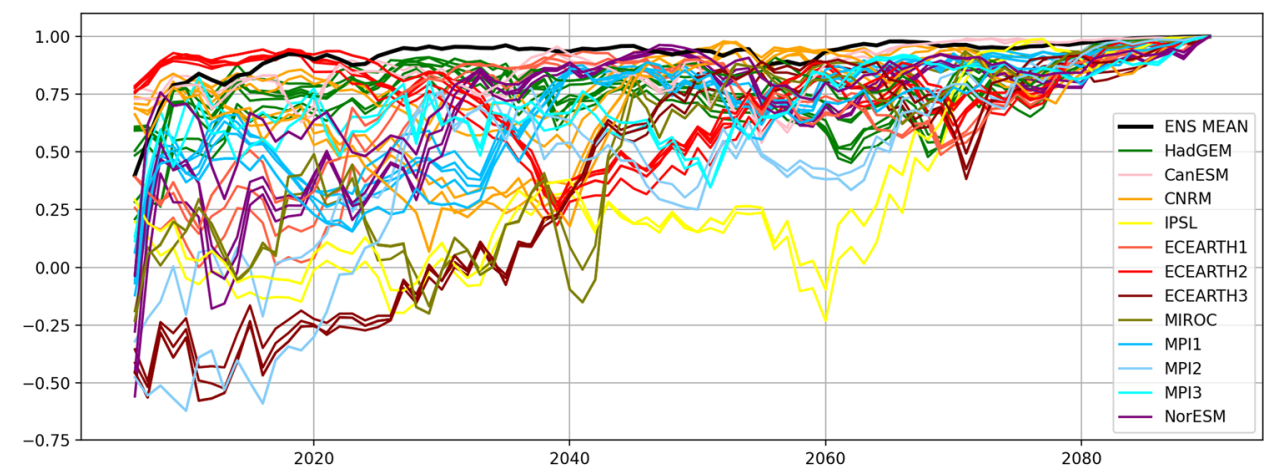


(EC-EARTH-r3i1p1) and HadGEM2 have some differences, but many more models are converging (Fig. 7). According to these results, the pattern already manifests itself as early as by 2020 , to a certain extent more so in autumn (Fig. 8). Individual models except IPSL, are even converging earlier in autumn than during any other season. This could be related to the retreat of sea ice, which is mostly pronounced in models in autumn. September, October, and November will be the months where all models basically lose all sea ice towards the end of the century for RCP8.5 (Lebrun et al. 2019). It is very important to realize that the pattern is emerging very early suggesting that if this was the case in the real world, then we should expect to see some similarities between models and observation in the autumn.
NorESM1-M seems to be an outlier for the spring season (Fig. 9).

Figures 10 and 11 show spatial correlation for $500-\mathrm{hPa}$ wind speed and MSLP for seasonal and yearly mean, respectively. The results show that the ensemble averages of scaled patterns of 500-hPa wind speed (Fig. 10) are emerging starting from about 2045 in all seasons. Ensemble means of MSLP (Fig. 11) are highly correlated from the 2020s compared to the end of the century except for winter. If we look at the individual model results, we see that they also have different responses depending very much on GCM ensemble member in winter (Supplementary Fig. S2). For most of the ensemble members, the pattern is emerging around 2040. However, ensemble members such as MPI1, ECEARTH2 and NorESM1-M have different behaviors which are like
Fig. 9 Correlation between a running mean of 20 -years scaled patterns of individual models and ensemble mean (black line) of 500-hPa geopotential height from 2006 to end-period levels (2080-2099) for spring season
Fig. 10 Correlation between a running mean of 20 -years ensemble mean scaled patterns of 500-hPa wind speed from 2006 to end-period levels (2080-2099)
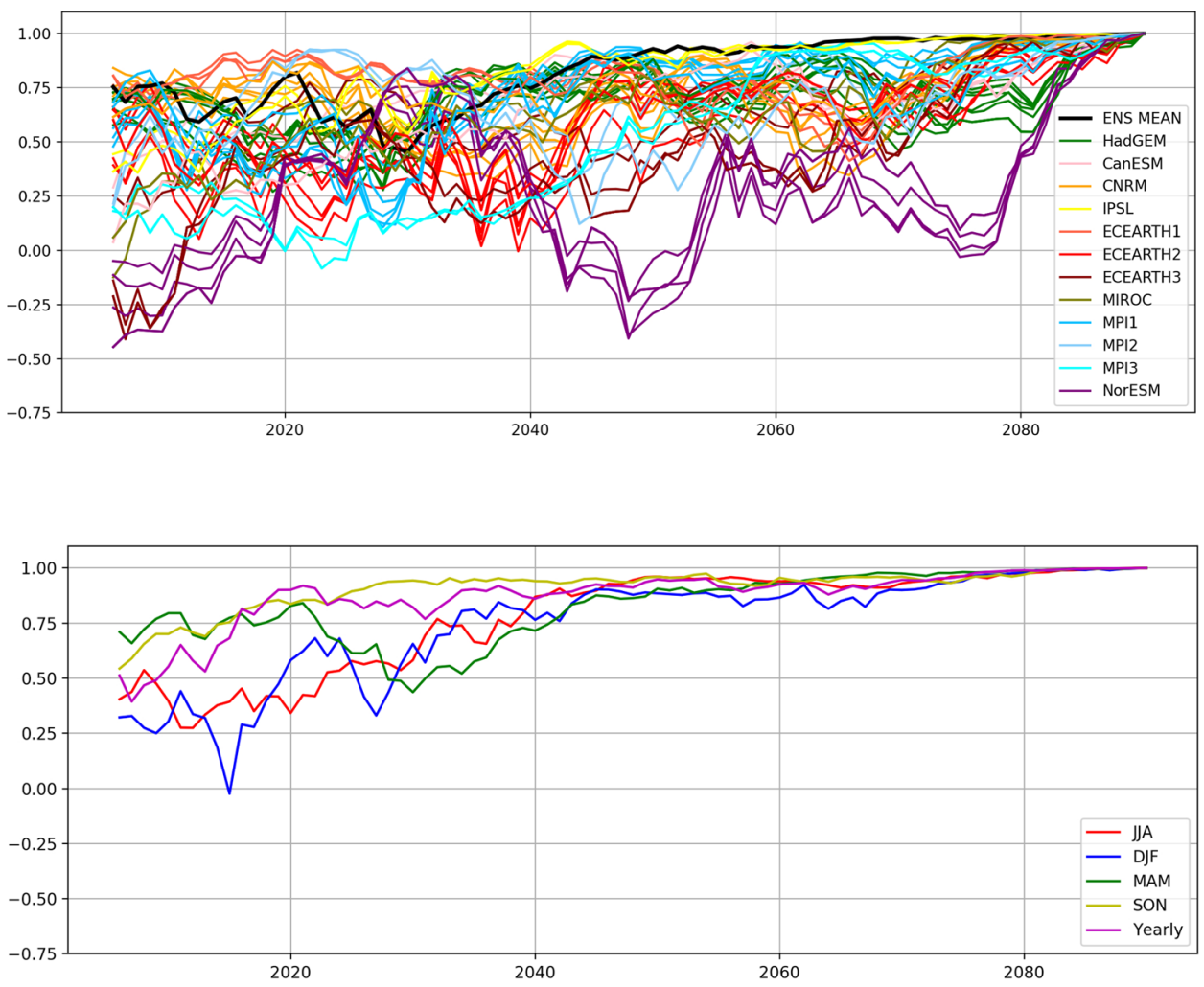

Fig. 11 Correlation between a running mean of 20-years ensemble mean of mean sea level pressure from 2006 to endperiod levels (2080-2099)

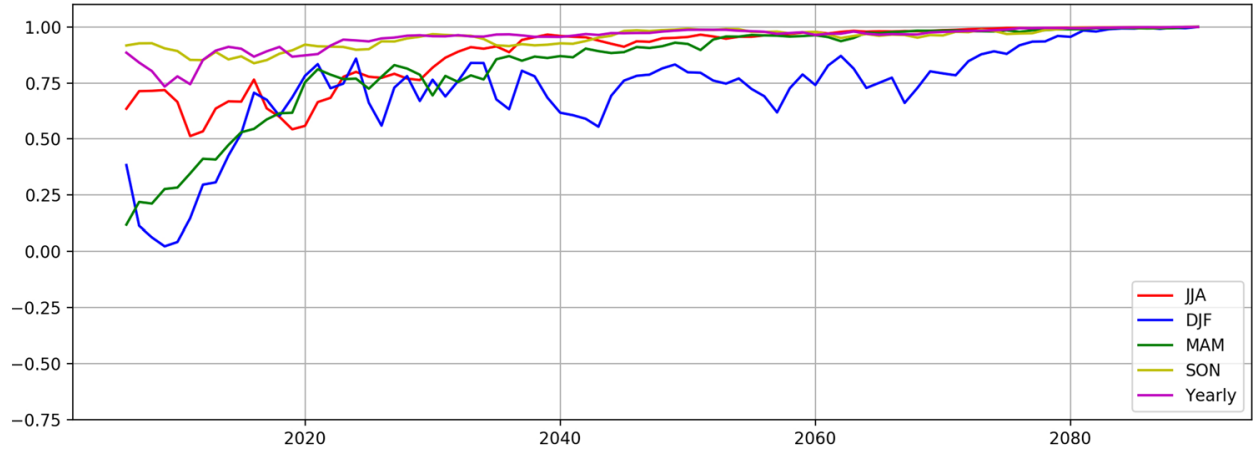


those in 500-hPa Gph for winter. They have more fluctuations compared to other ensemble members indicating that the patterns of change may not be persistent for those model ensemble members.

\subsection{Comparison between the scaled pattern and the different warming levels}

Here, we aim to investigate the persistence of the scaled patterns when compared with the results of different global warming levels (Matte et al. 2019). Figures 12 and 13 show the emergence of scaled patterns through the end of the century spatially for winter and summer seasons, respectively. The areas where $\mathrm{S} / \mathrm{N}<1$ are indicated by the gray shading. We used the $\mathrm{S} / \mathrm{N}$ metric to detect any robustness of the change signal. When the signal is greater than the inter-model spread ( $\mathrm{S} / \mathrm{N}>1)$, it is considered as robust. It is seen that a change signal in 500-hPa Gph (Fig. 12a-d and Fig. 13a-d) is robust for all seasons and for all time scales. A signal in MSLP, showing an increase over the Mediterranean during winter emerges above the noise as we increase the global warming level (Fig. 12k, 1). The S/N metric used at the grid-point level might not be a trustworthy method to determine robustness of change signal especially when it is small compared to the noise. Ensemble mean change in $500-\mathrm{hPa}$ wind speed is not considered as robust from a statistical $(\mathrm{S} / \mathrm{N})$ point of view since the change signal itself is very small (Fig. 12e-h). However, the pattern for wind speed change appears to be highly robust since the change pattern is also consistent with changes in 500-hPa Gph and MSLP. For the summer season, the pattern is there and emerges very early, starting about the time when the $1{ }^{\circ} \mathrm{C}$ pattern emerges (Fig. 13e-h).

\section{Discussion}

All climate models have their own decadal variability, which can differ by intensity and synchronicity with the observed evolution. In this section, we investigate if any of the most recent observed changes are in line with the emerging patterns of the end of the century deduced from the EUCORDEX simulations. To assess whether these emerging patterns may already exist under present conditions, we present seasonal change of scaled patterns of 500-hPa Gph (Fig. 14), scaled patterns of 500-hPa wind speed with the direction (Fig. 15) and MSLP (Fig. 16) using ERA5 dataset for the period of 2000-2019 compared to the period of 1980-1999. 500-hPa Gph and 500-hPa wind speed are scaled by the global mean temperature change. We observe
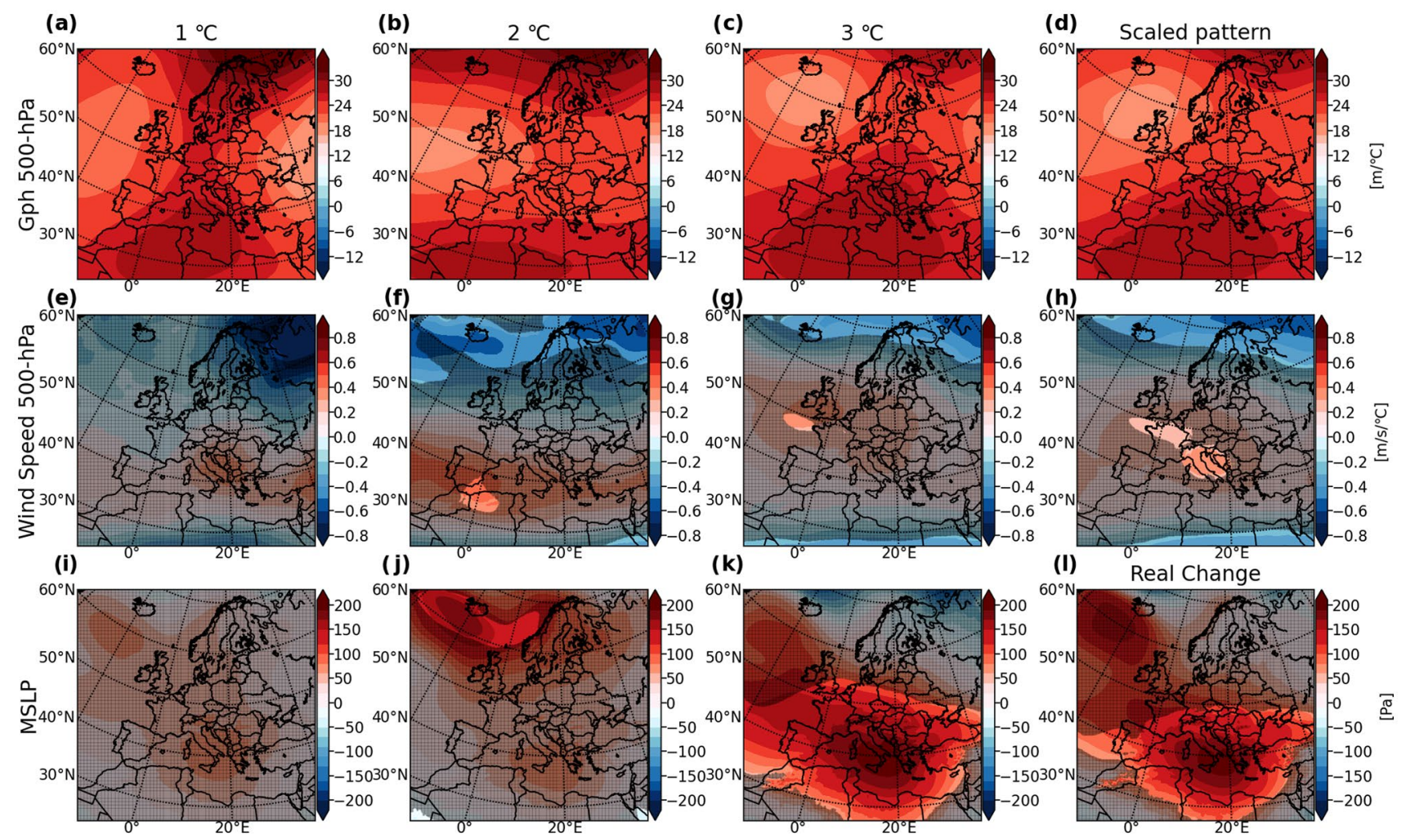

Fig. 12 DJF scaled 500-hPa geopotential height (a-d), scaled 500-hPa wind speed (e-h) and mean sea level pressure patterns (i-l) for the different warming levels of $1{ }^{\circ} \mathrm{C}(\mathrm{a}, \mathrm{e}, \mathrm{i}), 2^{\circ} \mathrm{C}(\mathbf{b}, \mathbf{f}, \mathbf{j}), 3^{\circ} \mathrm{C}(\mathbf{c}, \mathbf{g}, \mathbf{k})$ and for the end of the century $(\mathbf{d}, \mathbf{h}, \mathbf{l})$. Gray shading shows areas at which $\mathrm{S} / \mathrm{N}<1$ 

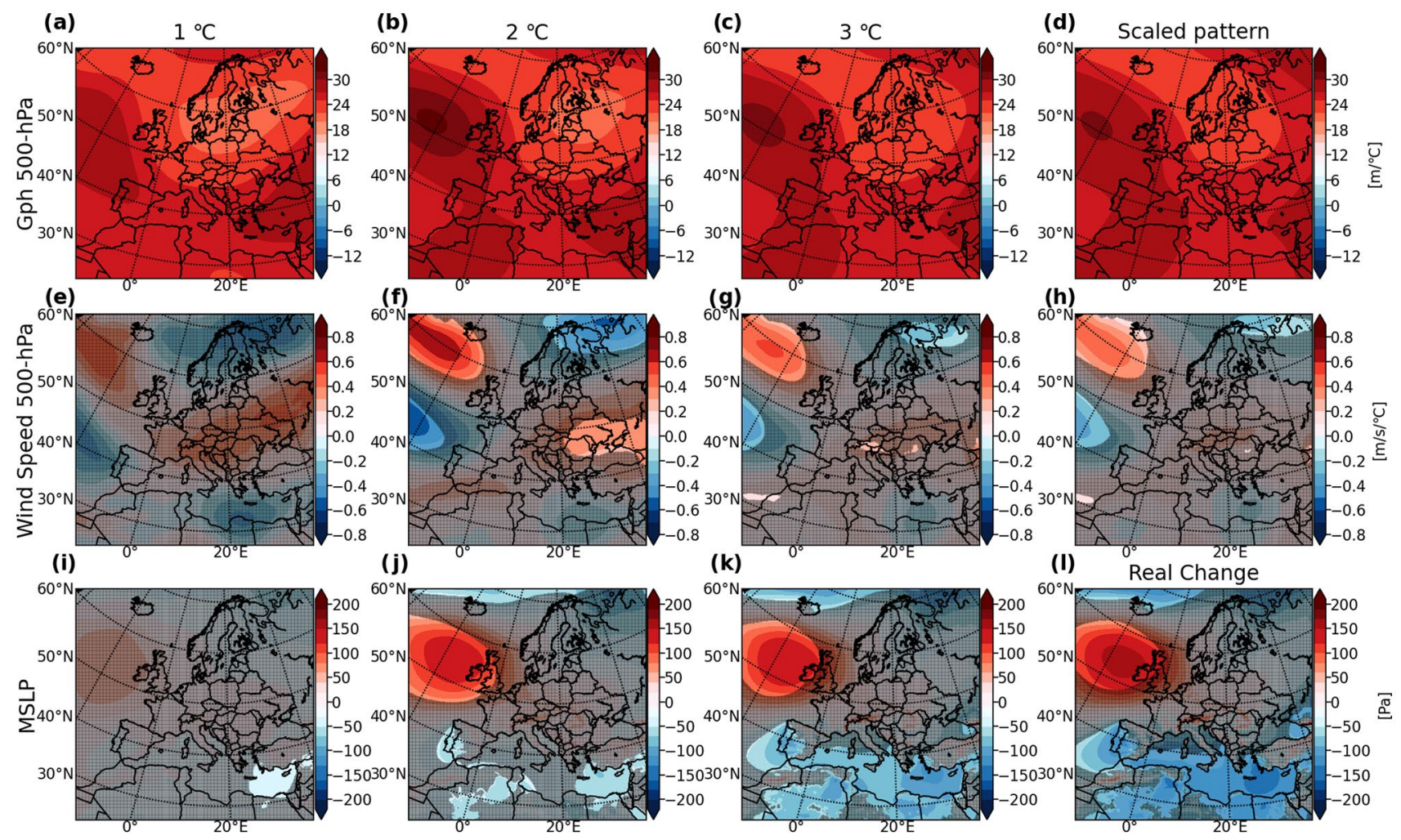

Fig. 13 JJA scaled 500-hPa geopotential height (a-d), scaled 500-hPa wind speed (e-h) and mean sea level pressure patterns (i-l) for the different warming levels of $1{ }^{\circ} \mathrm{C}(\mathbf{a}, \mathbf{e}, \mathbf{i}), 2{ }^{\circ} \mathrm{C}(\mathbf{b}, \mathbf{f}, \mathbf{j}), 3{ }^{\circ} \mathrm{C}(\mathbf{c}, \mathbf{g}, \mathbf{k})$ and for the end of the century $(\mathbf{d}, \mathbf{h}, \mathbf{l})$. Gray shading shows areas at which $\mathrm{S} / \mathrm{N}<1$

Fig. 14 Change in scaled patterns of 500-hPa geopotential height for the period of 2000 2019 compared to $1980-1999$ for four seasons (a-d) using ERA5 dataset (a)

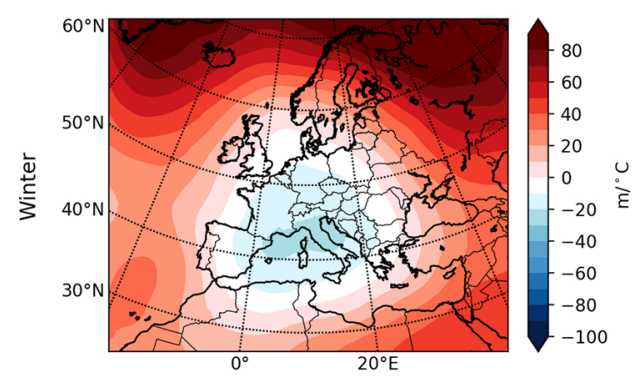

(c)

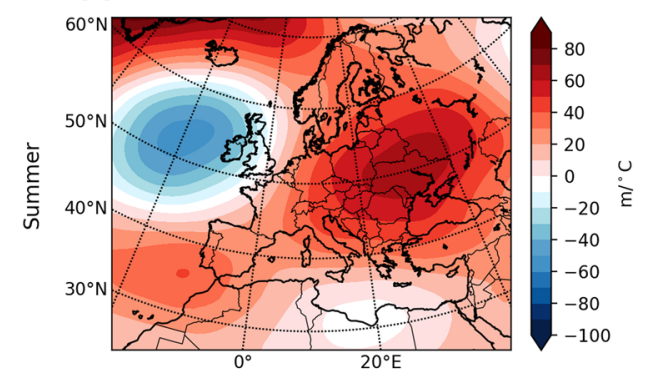

(b)

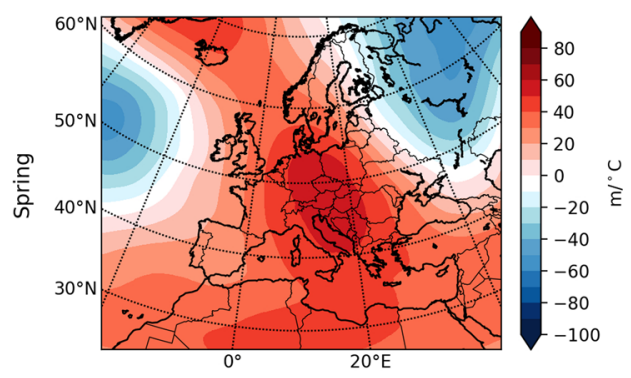

(d)

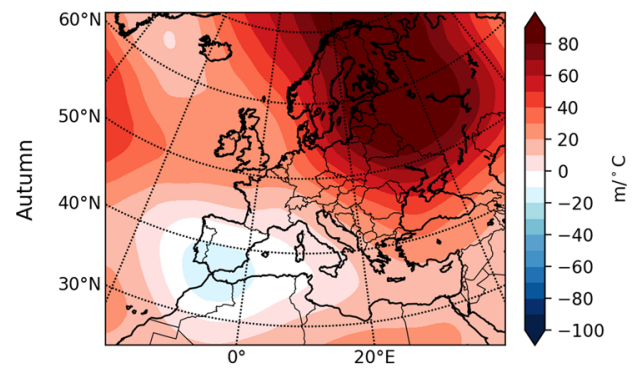

an increase in 500-hPa Gph over land particularly in summer, a slight decrease over the Mediterranean and Central Europe in winter and over the Iberian Peninsula in autumn and finally a strong decrease over northern part of Russia in spring (Fig. 14). Arctic amplification is also seen over the northern part of the domain especially in winter (Fig. 14a). There is a decrease in MSLP over the Mediterranean for all seasons, more pronounced during winter (Fig. 16a) together 
Fig. 15 Change in scaled patterns of 500-hPa wind speed for the period of 2000-2019 compared to 1980-1999 for four seasons (a-d) using ERA5 dataset. (Length of arrows are scaled to fit in the image)
Fig. 16 Change in patterns of mean sea level pressure for the period of 2000-2019 compared to $1980-1999$ for four seasons (a-d) using ERA5 dataset (a)

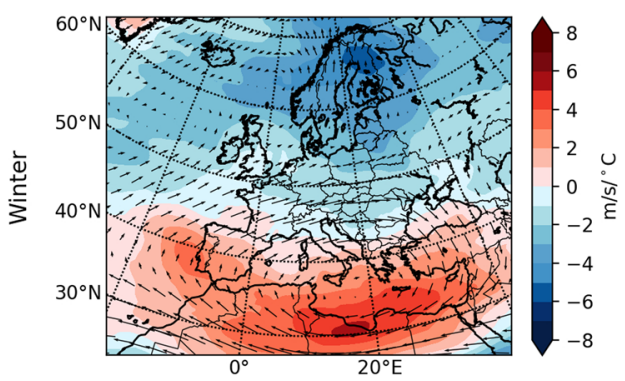

(c)

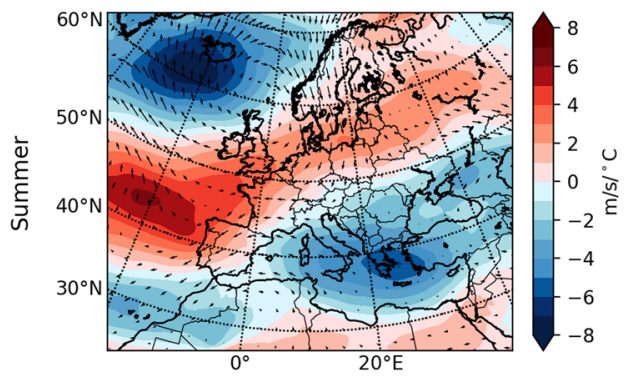

(b)

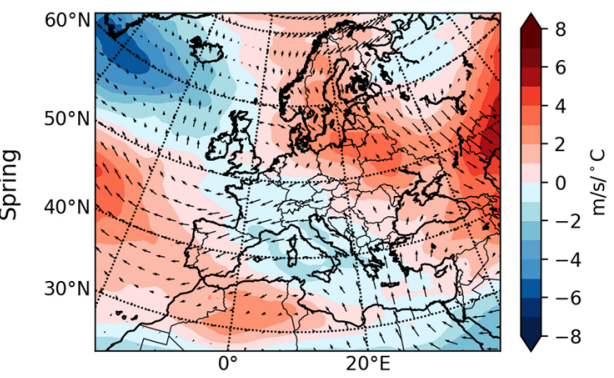

(d)

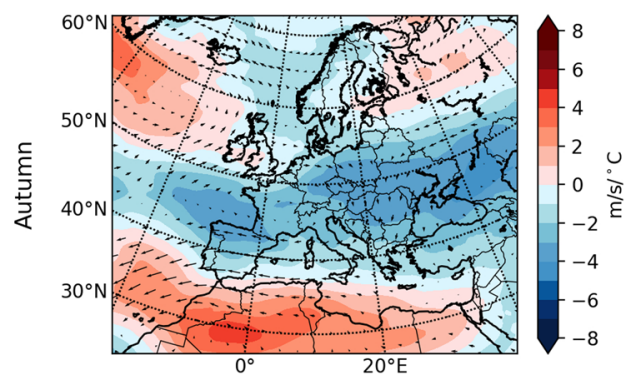

(a)

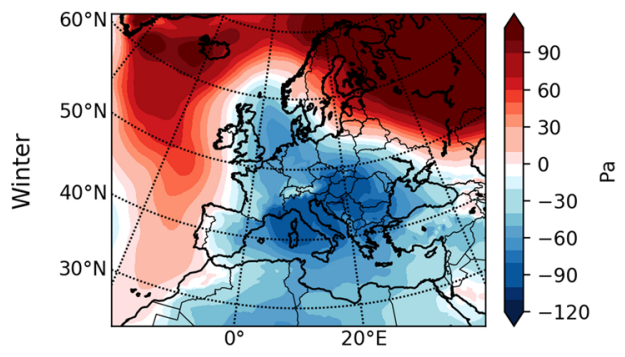

(c)

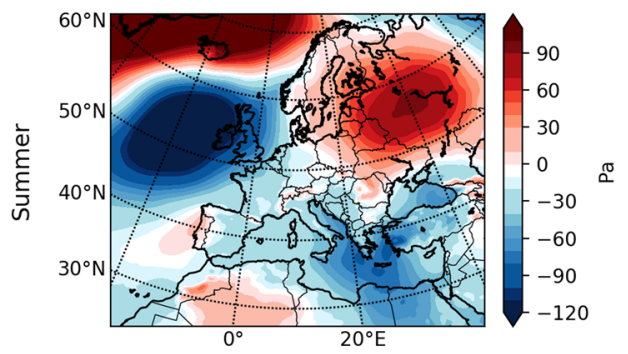

(b)

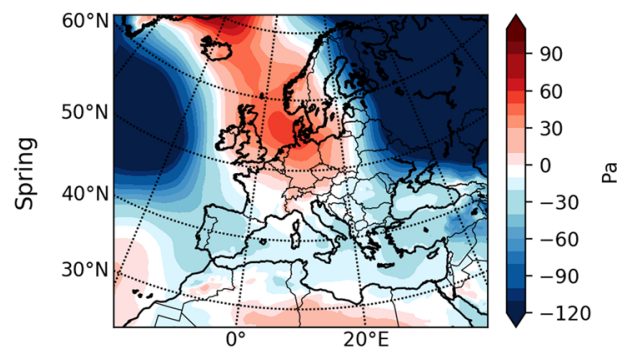

(d)

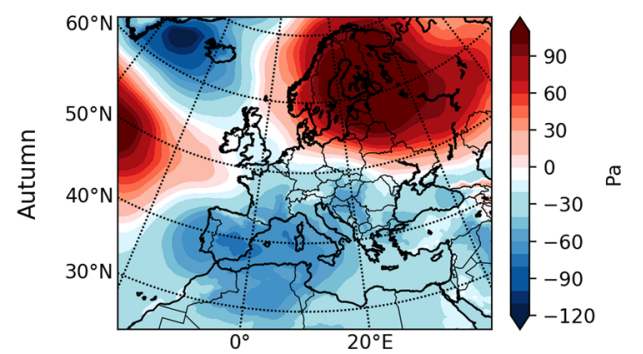

with an enhanced westerly flow over the northern of Mediterranean Sea and central Europe (Fig. 15a). When there are positive and negative changes, scaling becomes very sensitive to the scaling with global mean temperature, which for shorter periods will result in an extrapolation, as also done here in the ERA5 analyses.

We also compared trends of 500-hPa Gph in ERA5 with ensemble mean of model projections for 2000-2019. The reason behind picking up the last 20 year is the strong global warming trend. Except for a cooling trend over the Mediterranean in spring, there is a warming trend over all land areas particularly in summer and autumn according to ERA5 (Fig. 17). A tendency of stronger warming of central Europe is visible in all seasons in the ensemble mean of model projections (Supplementary Fig. S3). For summer, multi model mean results also exhibit warming. Although not over the exact same area (Supplementary Fig. S3c), it is comparable to the warming in ERA5 (Fig. 17c). Since the signal of the summer emerges around the 2030s, it should not be expected to have too many similarities for that period. We know from the model results that they are not all agreeing to the end of the century change pattern, but the pattern has the biggest 
(a)

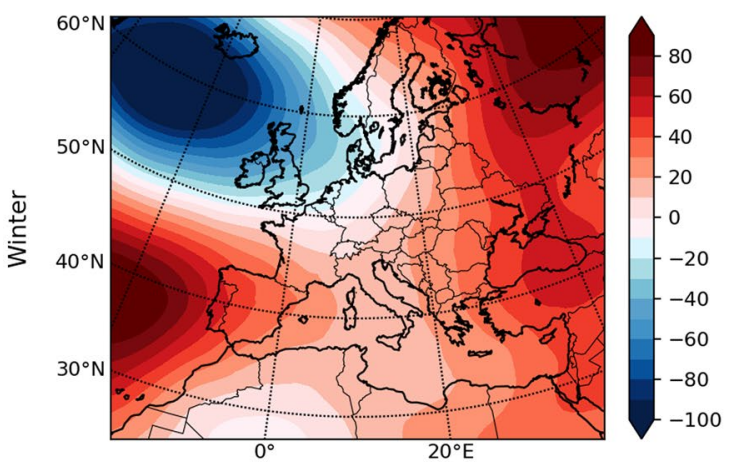

(c)

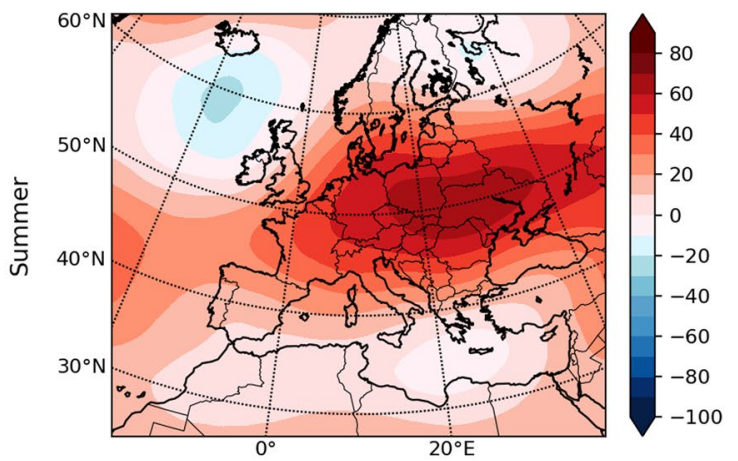

(b)

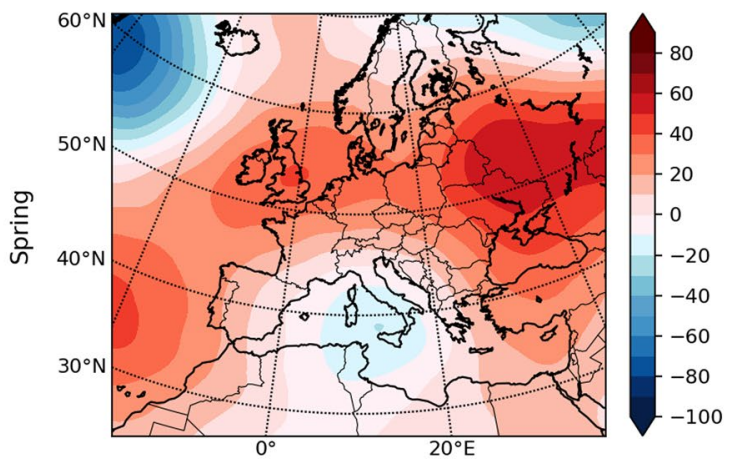

(d)

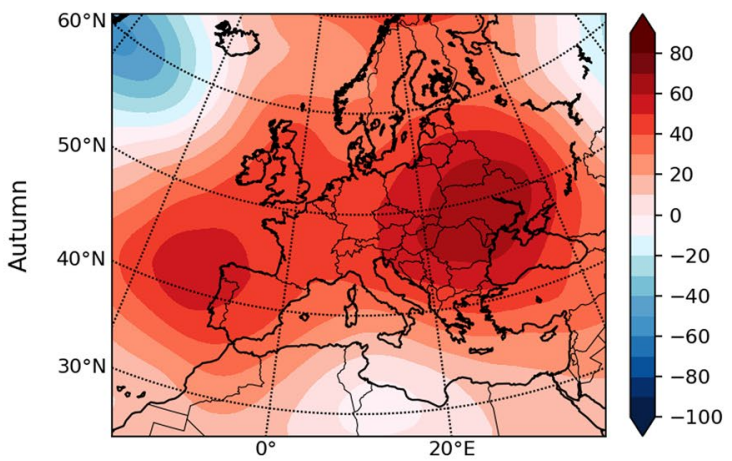

Fig. 17 500-hPa Geopotential height trends in ERA5 for the period of 2000-2019 for four seasons (a-d)

potential for being already emerging in autumn. There are indeed more similarities between model results and observations for autumn. There is the element of a quadrupole, with weak reduction over the Mediterranean and strong reduction over Iceland and then a ridge connecting areas with enhanced height (Supplementary Fig. S3d). We also see these two areas with enhanced high over Europe in the observed trends (Fig. 17d). It indicates that autumn could be the season, where we already have begun to see the emerging pattern of change being realized.

Ensemble mean of model results for all variables, especially in autumn, seems to be well correlated with the pattern of the end of the century, emphasizing that decadal variability is suppressed by taking the mean. The ensemble mean is a combination of individual models, and it is rising above the model variability. However, if we look at the individual models, they do not all agree on the positive correlation towards the end of the century. As a consequence of that, to look at the ensemble mean of circulation related results deserves a careful assessment (e.g., Christiansen 2018). It is important to note that the projected climate change will depend very much on the shifts in major modes of variability such as North Atlantic Oscillation or large-scale blocking patterns. Models are not projecting atmospheric circulation variability in the same way. In line with general findings, our results also implies that circulation is heavily driven by the GCM ensemble members so that there is really very little deviation between RCMs driven by the same GCM ensemble member especially on long-term average climate (e.g., Sanchez-Gomez et al. 2008). There are families of lines belonging to the same GCM ensemble member and they evolve in the same direction.

According to the results in autumn, there is a relatively early correlation with the end of the century patterns of change. This is clearly the period in which ensemble members suggest that the pattern emerges at the earliest. For other seasons, there are big fluctuations within individual models. It is important to note that the signal is not really emerging before $\sim 2050$ in winter. This is indicating that we cannot expect to see any agreement among the ensemble members already for that season. Discrepancy among the models for winter is pretty much related to the storm track and to the different treatment of sea ice in the GCM ensemble members. CMIP5 GCMs have relatively low skill of reproducing winter circulation patterns over Europe and the North Atlantic which has been shown to be related to an overestimation of the meridional pressure gradient (Brands et al. 2013; Wójcik 2015). This is explained by enhanced meridional pressure gradient that leads to an overestimation of westerlies carrying relatively warm and moist air 
to Europe and milder conditions than observed. Projections also indicate increase in the westerly circulation, which has an impact on temperature over Europe (Plavcová and Kyselý 2013; Otero et al. 2017; Stryhal and Huth, 2019a). This is also in line with results of the present study even though we on use a small set of GCMs (eight CMIP5 GCM modelstwelve CIMP5 GCM ensemble members).

Any small deviation from the pattern by the end century in the early phase has a strong imprint due to the scaling process since the global temperature change value (used to scale) is still small and may even have variation from year to year in the beginning. It is not a priori expected to see that there are elements that tend to show correlation at an early stage, for autumn even before being robust according to the $\mathrm{S} / \mathrm{N}$ metric. The ensemble mean suggests that the best estimate is in the autumn, since all the other seasons are less convincing. However, several model ensemble members show a good agreement with their end-of-the-century scaled pattern. For most of the seasons, the pattern does not emerge until later this century while emerging already around 2010 in autumn. Even if there is a large fraction of models which correlates well already in the beginning, some deviate later. However, if we look at the ensemble mean, the pattern emerges already before it is robust. Most of the individual models converge very quickly to the same pattern. This could be related to autumn being the season when sea ice and snow have a negligible impact. Several CMIP5 models show ice-free conditions by 2050 for September and low sea ice concentration for the rest of the autumn (Stroeve et al. 2012). In general, GCMs have a better performance in simulating 500-hPa Gph than in the case of MSLP, while the best model agreement occurs in the transition seasons (MAM and SON) for MSLP (Wójcik 2015).

Recently, Stryhal and Huth (2019b) validated atmospheric circulation over the Euro-Atlantic domain by using the historical runs from 32 CMIP5-GCMs during winter. They showed that CNRM-CM5 was optimal for simulating the frequency of circulation types calculated from daily SLP patterns and that EC-EARTH is a good model over the Eastern Mediterranean region. Brands et al (2013) also assessed the ability of seven Earth System Models from CMIP5 including six of global climate models used in this study to simulate present conditions over Europe. According to their results, HadGEM2-ES and MPI-ESMLR generally have better performance than the remaining models along the lateral boundaries of the EURO-CORDEX domain. They also found that the meridional pressure gradient is overestimated during winter and spring by most of the models including CanESM2, IPSL-CM5A-MR, MPI-ESMLR and NorESM1-M. They also show that CanESM2 and CNRM-CM5 underestimate SLP in summer over most of the land areas. Performance of IPSL-CM5-MR is generally poor, while MPI-ESM-LR and HadGEM2-ES outperform the remaining models. According to the study by Perez et al. (2014), EC-EARTH and HadGEM2-ES are among the seven models that outperformed the rest of 42 CMIP5 models during the twenty-first century over the north-east Atlantic region. They also emphasize that performance of GCMs depends on the study area, the considered variable and most importantly on the analyzed season. Those three studies were looking at the performance of CMIP5 GCMs in simulating atmospheric circulation related variables over Europe and the North Atlantic. Most of the GCMs used in this study were included in these studies as well.

Even though the relatively small set (12 underlying GCM ensemble member simulations) of GCM ensemble members used in this study compared to studies looking at the full CMIP5 dataset, results of the models seem to be robust by means of S/N metric. When the global warming exceeds certain level, there is an expansion of the atmosphere everywhere. The thickness of the atmosphere will increase since temperature is rising. Because of this physical principle, we should expect to see this expansion in most models. There might be a couple of model ensemble members which have very low climate sensitivity and cannot capture this physical argument. Otherwise, one would expect that it is very visible. On the other hand, the GCM ensemble member has a significant influence on the climate change signal compared to RCM especially for large scale fields. The specific GCMRCM pair has negligible effects on climate change whereas it is important for the mean climate (Christensen and Kjellström 2020). Even though some of the GCM ensemble members used in this study may have more influence on the ensemble mean due to the non-uniformly filled GCM-RCM matrix, results were also assessed individually. In addition, Collins et al. (2013; e.g., Fig. 12.18) showed that the full CMIP5 ensemble exhibit a general change in MSLP patterns that is similar to what we find. We are therefore confident that the EURO-CORDEX regional climate projections are representative of the CMIP5 models behavior.

Circulation change may itself be driven by a change in the radiative forcing. Most of the GCM ensemble members project on this new pattern very quickly. The difference between north and south is gradually enhanced as the pattern is emerging since the circulation effect as inherited from the driving GCM ensemble member is shown to further amplify the north-south temperature change gradient (Kröner et al. 2017). Warming is increasing differentially which changes the circulation. Because of this differential warming in winter and spring, westerly circulation is projected to be enhanced in ensemble mean results over the Mediterranean and Central Europe. Radiative forcing is apparently turning circulation changes on gradually. At some point, one should expect that it will not continue forever. If the heat continues to increase, we will see another regime. However, for most of the models, it appears to be linear but some of the models 
seem to have different regimes, e.g., switching between anticorrelation to correlation with the end of the century pattern. The models we have analyzed at the 20-year climate time scale do not in general show large excursions from a relatively simple converging over time of the climate change patterns towards the end of century pattern of the models. This may imply that models are not vigorous enough or that this may be representing a basic behavior of the climate system, which is difficult to judge from the 40-year of re-analysis at our hand. It is important to note that models are different in many respects and may respond in a very different way to external forcing, which offers a large spectrum of possibilities for spatial and temporal variability over time. Additionally, there are many different mechanisms and variables such as the lapse rate, albedo, relative humidity, and clouds which are all influencing climate change at a local scale and acting in different ways over different locations. They could be circulation dependent and, in the meantime, be also defining for circulation changes.

\section{Conclusion}

In this study, future circulation changes in scaled patterns of 500-hPa Gph and 500-hPa wind speed over Europe at the end of the century was investigated together with fields of MSLP using the data set consisting of RCM projections from EURO-CORDEX. In winter, an increase in 500-hPa Gph and MSLP associated with enhanced westerly flow which causes increase of anticyclonic circulation over the Mediterranean and Central Europe will lead to more stable conditions for the region. We identify a warming and slight change in wind fields over the region in summer. Ensemble mean of model projections generally show robust increase in 500-hPa Gph and MSLP and give reasonable results for wind speed consistent with changes in heights and pressure. The emergence of the scaled patterns was also investigated, and we showed that the ensemble mean pattern is emerging earlier than by the individual models. Models have different responses to circulation which is mostly dependent on GCM ensemble members. They tend to grow into stable patterns of circulation. Some of the models adjust very quickly to this new pattern and converge individually while others do not. It is interesting to note that the earliest emergence of the scaled pattern seems to appear in autumn. Even though scaling could make signal noisy at the beginning, pattern is already there around 2010. We would like to suggest that this is because of less influence of sea ice and snow in the autumn.

With the aim to see if models have some similarities with observed changes, we investigated the change of scaled patterns in observed variables for the last 20-year period of 2000-2019 compared to the first 20-year period of 1980-1999 using ERA5 dataset. Because results of end century scaled patterns show early emergence in autumn, we propose that it is the season in which we may have the best chance to find similar trends between model results and observation. According to our results, we may already see this increasing trend in the observations during autumn.

Supplementary Information The online version contains supplementary material available at https://doi.org/10.1007/s00382-021-06069-0.

Acknowledgements We acknowledge the World Climate Research Programme's CORDEX project for its role in making available the WCRP CORDEX multi-model data set, and we thank the climate modeling groups for producing and making available their model outputs.

Funding Tugba Ozturk was supported by the Scientific and Technological Research Council of Turkey (TUBITAK) under the programme TUBITAK 2219-International Postdoctoral Research Fellowship. This work also received support by the European Union under the Horizon 2020 Grant Agreement 776613, the EUCP project.

Data availability EURO-CORDEX dataset used in this study can be downloaded from the Earth System Grid Federation website (https:// esgf-data.dkrz.de/projects/cordex-dkrz/).

\section{Declarations}

Conflict of interest The authors declare that there is no conflict of interest.

Open Access This article is licensed under a Creative Commons Attribution 4.0 International License, which permits use, sharing, adaptation, distribution and reproduction in any medium or format, as long as you give appropriate credit to the original author(s) and the source, provide a link to the Creative Commons licence, and indicate if changes were made. The images or other third party material in this article are included in the article's Creative Commons licence, unless indicated otherwise in a credit line to the material. If material is not included in the article's Creative Commons licence and your intended use is not permitted by statutory regulation or exceeds the permitted use, you will need to obtain permission directly from the copyright holder. To view a copy of this licence, visit http://creativecommons.org/licenses/by/4.0/.

\section{References}

Beniston M, Stephenson DB, Christensen OB et al (2007) Future extreme events in European climate: an exploration of regional climate model projections. Clim Change 81:71-95. https://doi. org/10.1007/s10584-006-9226-z

Blackburn M, Methven J, Roberts N (2008) Large-scale context for the UK floods in summer 2007. Weather 63:280-288

Brands S, Herrera S, Fernández J, Gutiérrez JM (2013) How well do CMIP5 Earth System Models simulate present climate conditions in Europe and Africa? Clim Dyn 41:803-817. https://doi.org/10. 1007/s00382-013-1742-8

Brogli R, Kröner N, Sørland SL, Lüthi D, Schär C (2019) The role of hadley circulation and lapse-rate changes for the future European summer climate. J Climate 32(2):385-404 
Christensen JH, Christensen OB (2007) A summary of the PRUDENCE model projections of changes in European climate by the end of the century. Clim Change 81:7-30

Christensen OB, Kjellström E (2020) Partitioning uncertainty components of mean climate and climate change in a large ensemble of European regional climate model projections. Clim Dyn 54:42934308. https://doi.org/10.1007/s00382-020-05229-y

Christensen OB, Yang S, Boberg F, Maule CF, Thejll P, Olesen M et al (2015) Scalability of regional climate change in europe for high-end scenarios. Clim Res 64:25-38. https://doi.org/10.3354/ cr01286

Christensen JH, Larsen MAD, Christensen OB, Drews M, Stendel M (2019) Robustness of European climate projections from dynamical downscaling. Clim Dyn 53:4857-4869. https://doi.org/10. 1007/s00382-019-04831-z

Christensen JH, Krishna Kumar K, Aldrian E, An S-I, Cavalcanti IFA, de Castro M, Dong W, Goswami P, Hall A, Kanyanga JK, Kitoh A, Kossin J, Lau N-C, Renwick J, Stephenson D, Xie S-P, Zhou T (2013) Climate Phenomena and their Relevance for Future Regional Climate Change. In: Stocker TF, Qin D, Plattner G-K, Tignor M, Allen SK, Boschung J, Nauels A, Xia Y, Bex V, Midgley PM (eds) Climate Change 2013: The Physical Science Basis. Contribution of Working Group I to the Fifth Assessment Report of the Intergovernmental Panel on Climate Change. Cambridge University Press, Cambridge, United Kingdom and New York, NY, USA, pp 1217-1308. doi: https://doi.org/10.1017/CBO97 81107415324.028

Christiansen B (2018) Ensemble averaging and the curse of dimensionality. J Climate 31(4):1587-1596

Collins M, Knutti R, Arblaster J, Dufresne J-L, Fichefet T, Friedlingstein P, Gao X, Gutowski WJ, Johns T, Krinner G, Shongwe M, Tebaldi C, Weaver AJ, Wehner M (2013) Long-term climate change: projections, commitments and irreversibility. In: Stocker TF, Qin D, Plattner G-K, Tignor M, Allen SK, Boschung J, Nauels A, Xia Y, Bex V, Midgley PM (eds) Climate change 2013: the physical science basis. Contribution of Working Group I to the Fifth Assessment Report of the Intergovernmental Panel On Climate Change. Cambridge University Press, Cambridge.

Coppola E, Nogherotto R, Ciarlo' JM, Giorgi F, van Meijgaard E, Kadygrov N, et al (2021) Assessment of the European climate projections as simulated by the large EURO-CORDEX regional and global climate model ensemble. J Geophys Res Atmos 126(4), e2019JD032356.

Coumou D, Lehmann J, Beckmann J (2015) The weakening summer circulation in the Northern Hemisphere mid-latitudes. Science 348:324-327

Coumou D, Di Capua G, Vavrus S, Wang L, Wang S (2018) The influence of Arctic amplification on mid-latitude summer circulation. Nat Commun 9:2959. https://doi.org/10.1038/ s41467-018-05256-8

Déqué M, Rowell DP, Lüthi D, Giorgi F et al (2007) An intercomparison of regional climate simulations for Europe: assessing uncertainties in model projections. Clim Change 81(1):53-70

Dong B, Sutton RT, Woollings T, Hodges K (2013) Variability of the North Atlantic summer storm track: mechanisms and impacts on European climate. Environ Res Lett 8:034037

Fischer E, Schär C (2010) Consistent geographical patterns of changes in high-impact European heatwaves. Nature Geosci 3:398-403. https://doi.org/10.1038/ngeo866

Francis JA, Vavrus SJ (2012) Evidence linking Arctic amplification to extreme weather in mid-latitudes. Geophys Res Lett 39:L06801

Frederiksen CS, Ying K, Grainger S, Zheng X (2018) Modes of interannual variability in northern hemisphere winter atmospheric circulation in CMIP5 models: evaluation, projection and role of external forcing. Clim Dyn 50:2845-2865

Giorgi F, Lionello P (2008) Climate change projections for the Mediterranean region. Glob Planet Chang 63:90-104. https://doi.org/ 10.1016/j.gloplacha.2007.09.005

Hawkins E, Sutton R (2009) The potential to narrow uncertainty in regional climate predictions. Bull Am Meteorol Soc 90:1095-1107

Hersbach H, Bell B, Berrisford P, Biavati G, Horányi A, Muñoz Sabater J, Nicolas J, Peubey C, Radu R, Rozum I, Schepers D, Simmons A, Soci C, Dee D, Thépaut J-N (2019) ERA5 monthly averaged data on pressure levels from 1979 to present. Copernicus Climate Change Service (C3S) Climate Data Store (CDS). (Accessed on < 04-FEB-2020 >), https://doi.org/10.24381/cds.6860a573.

Horton D, Johnson N, Singh D et al (2015) Contribution of changes in atmospheric circulation patterns to extreme temperature trends. Nature 522:465-469. https://doi.org/10.1038/nature14550

Hurrell JW (1995) Decadal trends in the North Atlantic Oscillation: regional temperatures and precipitation. Science 269:676-679

Iversen T, Bentsen M, Bethke I, Debernard JB, Kirkevåg A, Seland $\varnothing$, Drange H, Kristjansson JE, Medhaug I, Sand M, Seierstad IA (2013) The Norwegian Earth System Model, NorESM1-M-Part 2: Climate response and scenario projections. Geosci Model Dev 6:389-415. https://doi.org/10.5194/gmd-6-389-2013

Jacob D, Petersen J, Eggert B et al (2014) EURO-CORDEX: new high-resolution climate change projections for European impact research. Reg Environ Change 14:563-578. https://doi.org/10. 1007/s10113-013-0499-2

Kjellström E, Nikulin G, Hansson U, Strandberg G, Ullerstig A (2011) 21st century changes in the European climate: uncertainties derived from an ensemble of regional climate model simulations. Tellus 63A:24-40

Kjellström E, Thejll P, Rummukainen M, Christensen JH, Boberg F, Christensen OB, Maule CF (2013) Emerging regional climate change signals for Europe under varying large-scale circulation conditions. Clim Res 56(2):103-119. https://doi.org/10.3354/ cr01146

Kjellström E, Nikulin G, Strandberg G, Christensen OB, Jacob D, Keuler K, Lenderink G, van Meijgaard E, Schär C, Somot S, Sørland SL, Teichmann C, Vautard R (2018) European climate change at global mean temperature increases of 1.5 and $2{ }^{\circ} \mathrm{C}$ above pre-industrial conditions as simulated by the EUROCORDEX regional climate models. Earth Syst Dynam 9:459478. https://doi.org/10.5194/esd-9-459-2018

Kröner N, Kotlarski S, Fischer E et al (2017) Separating climate change signals into thermodynamic, lapse-rate and circulation effects: theory and application to the European summer climate. Clim Dyn 48:3425-3440. https://doi.org/10.1007/ s00382-016-3276-3

Lebrun M, Vancoppenolle M, Madec G, Massonnet F (2019) Arctic sea-ice-free season projected to extend into autumn. Cryosphere 13:79-96. https://doi.org/10.5194/tc-13-79-2019

Lehmann J, Coumou D (2015) The influence of mid-latitude storm tracks on hot, cold, dry and wet extremes. Sci Rep 5:17491. https://doi.org/10.1038/srep17491

Matte D, Larsen MAD, Christensen OB, Christensen JH (2019) Robustness and scalability of regional climate projections over Europe. Front Environ Sci 6:163

Meehl GA, Stocker TF, Collins WD, Friedlingstein P et al (2007) Global climate Projections. In: Solomon S, Qin D, Manning M, Chen $\mathrm{Z}$ et al (eds) Climate change 2007: the physical science basis. Contribution of Working Group I to the Fourth Assessment 
Report of the Intergovernmental Panel on Climate Change. Cambridge University Press, Cambridge, pp 747-846

Otero N, Sillmann J, Butler T (2018) Assessment of an extended version of the Jenkinson-Collison classification on CMIP5 models over Europe. Clim Dyn 50:1559-1579. https://doi.org/10.1007/ s00382-017-3705-y

Perez J, Menendez M, Mendez FJ et al (2014) Evaluating the performance of CMIP3 and CMIP5 global climate models over the north-east Atlantic region. Clim Dyn 43:2663-2680. https://doi. org/10.1007/s00382-014-2078-8

Plavcová E, Kyselý J (2013) Projected evolution of circulation types and their temperatures over Central Europe in climate models. Theor Appl Climatol 114:625-634. https://doi.org/10.1007/ s00704-013-0874-4

Rajczak J, Schär C (2017) Projections of Future Precipitation Extremes Over Europe: A Multimodel Assessment of Climate Simulations. J Geophys Res Atmos 122:10,773-10,800. doi:https://doi.org/10. 1002/2017JD027176

Sanchez-Gomez E, Somot S, Déqué M (2008) Ability of an ensemble of regional climate models to reproduce weather regimes over Europe-Atlantic during the period 1961-2000. Clim Dyn 33:723-736

Schaer C, Vidale PL, Luethi D, Frei C, Haeberli C, Liniger MA, Appenzeller C (2004) The role of increasing temperature variability in European summer heatwaves. Nature 427:332-336

Shepherd T (2014) Atmospheric circulation as a source of uncertainty in climate change projections. Nature Geosci 7:703-708. https:// doi.org/10.1038/ngeo2253

Spinoni J, Vogt JV, Barbosa P, Dosio A, McCormick N, Bigano A et al (2018) Changes of heating and cooling degree-days in Europe from 1981 to 2100. Int J Climatol 38:e191-e208. https://doi.org/ $10.1002 /$ joc. 5362

IPCC (2013) Stocker TF, Qin D, Plattner G-K, Tignor M, Allen SK, Boschung J, Nauels A, Xia Y, Bex V, Midgley PM (eds) Climate
Change 2013: The Physical Science Basis. Contribution of Working Group I to the Fifth Assessment Report of the Intergovernmental Panel on Climate Change. Cambridge University Press, Cambridge, United Kingdom and New York, NY, USA https:// doi.org/10.1017/CBO9781107415324.

Stott PA, Stone DA, Allen MR (2004) Human contribution to the European heatwave of 2003. Nature 432:610-644

Stroeve JC, Kattsov V, Barrett A, Serreze M, Pavlova T, Holland M, Meier WN (2012) Trends in Arctic sea ice extent from CMIP5, CMIP3 and observations. Geophys Res Lett 39:L16502. https:// doi.org/10.1029/2012GL052676

Stryhal J, Huth R (2019a) Trends in winter circulation over the British Isles and central Europe in twenty-first century projections by 25 CMIP5 GCMs. Clim Dyn 52:1063-1075. https://doi.org/10.1007/ s00382-018-4178-3

Stryhal J, Huth R (2019b) Classifications of winter atmospheric circulation patterns: validation of CMIP5 GCMs over Europe and the North Atlantic. Clim Dyn 52:3575-3598. https://doi.org/10. 1007/s00382-018-4344-7

van Ulden AP, van Oldenborgh GJ (2006) Large-scale atmospheric circulation biases and changes in global climate model simulations and their importance for climate change in Central Europe. Atmos Chem Phys 6:863-881. https://doi.org/10.5194/acp-6-863-2006

Wójcik R (2015) Reliability of CMIP5 GCM simulations in reproducing atmospheric circulation over Europe and the North Atlantic: a statistical downscaling perspective. Int J Climatol 35:714-732. https://doi.org/10.1002/joc.4015

Publisher's Note Springer Nature remains neutral with regard to jurisdictional claims in published maps and institutional affiliations. 